\title{
LA BIO-ECOLOGÍA DE ORTEGA Y GASSET ${ }^{1}$
}

\author{
MARCOS ALONSO FERNÁNDEZ \\ Universidad de Investigación en Tecnología Experimental, Yachay, Ecuador
}

\begin{abstract}
RESUMEN: En este artículo trataremos de reflexionar, con la ayuda del filósofo español Ortega y Gasset, sobre la posibilidad de una bio-ecología que problematice algunos de los enfoques y premisas habitualmente asumidos en ecología. Tras mostrar que la filosofía orteguiana es una filosofía radicalmente ecológica -y una pionera en este aspecto-, mostraremos cómo las categorías de la razón vital armonizan perfectamente con algunos de los más recientes desarrollos biológicos que nos exigen pensar en conexión más estrecha a organismos y entornos.
\end{abstract}

PALABRAS CLAVE: Ortega y Gasset; ecología; biología; razón vital; organismo; entorno.

\section{Ortega y Gasset's bio-ecology}

ABSTRACT: In this article we will try to reflect, with Spanish Philosopher Ortega y Gasset's help, about the possibility of a bio-ecology that problematises some of the approaches and assumptions typically assumed in ecology. After showing that orteguian philosophy is a radical ecological philosophy and a pioneer in that aspect-, we will show how vital reason's categories perfectly harmonise with some of the most recent biological research that demand thinking organism and environment in closer connection.

KEY WORDS: Ortega y Gasset; ecology; biology; vital reason; organism; environment.

\section{INTRODUCCIÓN}

La juventud de la ecología no ha impedido que en sus pocas décadas de existencia haya dejado atrás un volumen notable de trabajos. Dar cuenta de los orígenes y del desarrollo de la ecología como disciplina, así como de sus distintas y heterogéneas corrientes, desborda los propósitos de este trabajo. Lo que intentaremos en las siguientes líneas será más bien dar un paso atrás y reflexionar, con la ayuda del pensamiento del filósofo español Ortega y Gasset, sobre la fundamentación de lo que denominaremos como una bio-ecología que problematice algunos de los enfoques y premisas habitualmente asumidos en ecología.

La elección de la filosofía de Ortega y Gasset para esta tarea no es gratuita. La icónica frase orteguiana "Yo soy yo y mi circunstancia, y si no la salvo a ella no me salvo yo» (I 757) ${ }^{2}$ ya ha puesto sobre aviso a muchos estudiosos del trasfondo ecológico de la filosofía de Ortega. Definiciones clásicas de la ecología como las de Ricklefs - «el estudio del entorno natural y de las relaciones de

1 Este artículo se enmarca en el Proyecto de investigación: «La condición humana ante los retos de la Ecología» de la Cátedra Francisco José Ayala de Ciencia, Tecnología y Religión de la Universidad Pontificia Comillas (2016-2019).

2 Para las obras de Ortega citaremos haciendo referencia al tomo de las Obras completas (Ortega y Gasset, J., Obras completas, Taurus, Madrid 2004-2010) en numeración latina seguido del número de página correspondiente. 
los organismos entre sí y con sus alrededores»³ - o la definición esbozada por Begon, Harper, y Townsend - «el estudio científico de las interacciones entre los organismos y su entorno» ${ }^{4}$ - , no pueden más que poner de manifiesto, en su evidente similitud con la frase orteguiana, la raigambre ecológica de la filosofía de Ortega.

Sin embargo, «Yo soy yo y mi circunstancia, y si no la salvo a ella no me salvo yo» sólo sería la punta del iceberg del ecologismo orteguiano y de la fecundidad ecológica de su propuesta. Por motivos que expondremos a continuación, la propuesta filosófica de Ortega tiene la doble virtud de ser una filosofía constitutivamente ecológica - o bio-ecológica, como discutiremos- y de ser muy anterior a todos los desarrollos ecológicos de la segunda mitad del siglo XX. Esta anterioridad se considera aquí una virtud en tanto que nos permite aproximarnos al fenómeno ecológico con nuevos ojos, evitando caer en ciertas categorías ya muy asentadas que, sin embargo, crean dificultades insuperables en la comprensión de ciertos problemas centrales de la propia ecología.

\section{Ortega y la ecología}

Que la filosofía de Ortega es una filosofía ecológica, o que al menos su propuesta está estrechamente relacionada con la ecología, es algo que ya ha sido defendido en otras ocasiones. De manera muy temprana, en 1973, José Luis Aranguren presentó una comunicación, después transcrita en forma de artículo, que se tituló «Ecología y comunicación en el pensamiento de Ortega y Gasset »5. La tesis que Aranguren defenderá, si bien reducida en cuanto a su alcance, concuerda con lo que aquí defenderemos, pues, como expone Aranguren, si bien «Ortega no habló de Ecología, la influencia sobre su pensamiento de la ciencia biológica de la época es muy visible» ${ }^{6}$. Diez años después, de manera más clara todavía, aunque también en un texto de poco alcance, Jordano Barea hablará de «Ortega y la Ecología de Jacobo von Uexküll»». Como el propio título indica, y como ya acertadamente apuntó Aranguren años atrás, Jordano Barea pone en directa relación la ecología orteguiana con su atención y fascinación por la biología de su tiempo, concretamente por las fértiles reflexiones biológicas de J. von Uexküll. Jordano Barea es taxativo sobre este punto, afirmando que Ortega

3 Ricklefs, R., Ecology, W. H. Freeman, New York 1990, p. 3 (traducción propia).

4 Begon, M., Harper, J. and Townsend, C., Ecology: Individuals, Populations, and Communities, Blackwell Science, Oxford 1990 (traducción propia).

5 Aranguren, J. L., «Ecología y comunicación en el pensamiento de Ortega.» en: Sistema. Revista de Ciencias Sociales, $\mathrm{n}^{\circ} 1$ (1973) 51-58.

6 Ibid., p. 51.

7 Jordano Barea, D., «Ortega y la ecología de Jacobo von Uexküll.» en: Boletín de la Real Academia de Córdoba, no 105 (1983) 108-111. 
«basó su filosofía vital en un libro de ecología, cuando la mayoría de los biólogos apenas prestaba atención a esta rama, entonces naciente, de las ciencias de la naturaleza, y cómo transportó los conceptos básicos de Uexküll al pentagrama filosófico, con admirable belleza literaria» ${ }^{8}$.

Esta idea de que la filosofía vital orteguiana se basa en un libro de ecología podría parecer algo exagerada, pero, como habremos de ver, no está tan lejos de la realidad como pudiera creerse. Ortega mismo ya reconoció de manera clara y reiterada su deuda con Uexküll, algo raro en el filósofo español, que no acostumbraba a explicitar sus fuentes. Además de diversos textos donde refiere, implícita y explícitamente, los trabajos del biólogo alemán, en 1922 Ortega manda traducir Ideas para una concepción biológica del mundo ${ }^{9}$ de Uexküll, y le antepone un prólogo donde desliza la siguiente importante confesión:

«Debo declarar que sobre mí han ejercido, desde 1913, gran influencia estas meditaciones biológicas. Esta influencia no ha sido meramente científica, sino cordial. No conozco sugestiones más eficaces que las de este pensador, para poner orden, serenidad y optimismo sobre el desarreglo del alma contemporánea» (III 415).

Es importante reconocer el carácter global, filosófico y no restringido, que Ortega otorga a la obra de Uexküll. Por eso nos parece muy acertada la tesis de Jordano Barea de que «el papel básico que Ortega concede a la circunstancia (...) parte de un saber científico de ecología pura» ${ }^{10}$; una idea que este autor remarca algunas páginas después cuando comenta que «La impregnación ecológica de Ortega, a través de Uexküll, es tal que para él «La vida es, esencialmente, un diálogo con el contorno" ${ }^{11}$. Y es principalmente al biólogo alemán a quien se refiere cuando el filósofo español expone las bases de una de sus ideas fundamentales explicando que «La ciencia biológica más reciente estudia el organismo vivo como una unidad compuesta del cuerpo y su medio particular: de modo que el proceso vital no consiste sólo en una adaptación del cuerpo a su medio, sino también en la adaptación del medio a su cuerpo.» (I 756-757). Volveremos un poco después sobre la base biológica de este ecologismo orteguiano, pero se puede adelantar que ahí estará el origen de sus anticipaciones o, si quiere, de su profetismo ecológico.

Si seguimos la línea temporal de esta reivindicación del ecologismo orteguiano nos encontramos a autores como Mariano Álvarez ${ }^{12}$, y Vicente Bellver, quien llegó a hablar de un "Ortega ecológico» ${ }^{13}$. También muy

\section{Ibid., p. 111.}

9 VON UEXKÜLL, J., Ideas para una concepción biológica del mundo, Espasa-Calpe, Buenos Aires 1945.

10 JoRdano Barea, D., op. cit., p.107.

11 Ibíd., p. 110.

12 Álvarez, M., «El concepto de cosa en Ortega.» en: Paredes, $M^{\mathrm{a}} \mathrm{C}$., El hombre y su medio. Perspectivas ecológicas desde Ortega y Gasset, Publicaciones Universidad Salamanca, Salamanca 1998, p. 102.

13 Bellver, V., Ecología: de las razones a los derechos, Comares, Granada 1994, p. 66-67. 
destacable fue el esfuerzo colectivo, unos años después, de la obra El hombre y su medio. Perspectivas ecológicas desde Ortega y Gasset ${ }^{14}$, editada por María del Carmen Paredes, y del que cabe destacar el capítulo de Luciano Espinosa titulado "La técnica como radical ecología humana» ${ }^{15}$. Sin embargo, por sorprendente que parezca, la comprensión de Ortega como ecologista ya había comenzado bastantes años atrás en Estados Unidos, donde algunos reputados ecologistas reivindicaron el pensamiento de Ortega como la primera filosofía ecológica propiamente dicha. El primero en llamar la atención sobre Ortega fue Paul Shepard, quien, como explica Beneite-Martí16, incluso mandó traducir e introdujo la versión en inglés de Prólogo a Veinte años de caza mayor del conde de Yebes, titulado en inglés Meditations on hunting, en una fecha tan temprana como 1972. En dicha introducción, Shepard elogia a Ortega por haber anticipado con mucha antelación lo que denomina como una «verdadera ecología del hombre» ${ }^{17}$. Algunos años después, sin salir de Norteamérica, Kim Rogers dedicará varios trabajos a esta problemática de la ecología en Ortega. En su artículo «Ortega and Ecological Philosophy» Rogers declarará, sin ambages, que:

«La filosofía de la razón vital orteguiana, una filosofía preocupada por entender todo desde el sistema inherente "mi vida", es la primera expresión de una aproximación ecológica en filosofía» ${ }^{18}$.

Al igual que Shepard, Rogers remarca el hecho de que Ortega se adelantara a toda la tradición ecológica en muchos años ${ }^{19}$. En este sentido, Rogers mencionará como anticipaciones ecológicas la idea de «vida como coexistencia» de Adán en el paraíso ${ }^{20}$; el perspectivismo de El tema de nuestro tiempo ${ }^{21}$; y la profundización sobre estas concepciones presentes en ¿Qué es filosofía? y sus cursos de los años treinta. Cabría aquí aclarar que el concepto de coexistencia de Adán en el paraíso tiene todavía una base demasiada neokantiana, y, como explica el propio Rogers ${ }^{22}$, tiene por ello una connotación demasiado estática que Ortega, no obstante, superará en su filosofía madura de los años treinta al enfatizar la relación ejecutiva, dinámica, que siempre existe entre yo y circunstancia.

14 Paredes Martín, M ${ }^{\mathrm{a}}$ C. (Ed.), El hombre y su medio. Perspectivas ecológicas desde Ortega y Gasset, Publicaciones Universidad Salamanca, Salamanca 1998.

15 Espinosa Rubio, L., "La técnica como radical ecología humana» en: Paredes, $\mathrm{M}^{\mathrm{a}} \mathrm{C}$., op. cit., pp. 119-142.

16 Beneite-Martí, J., José Ortega y Gasset y Ramon Margalef i López. Dos fuentes para la constitución de una perspectiva ecológica (tesis doctoral), Universitat de València, Valencia 2017, p. 223.

17 ShePard, P., «Introduction.» in: Meditations on hunting, Wilderness Adventure Press, Belgrade 1972, p. 18.

18 Rogers, K. W., "Ortega and EcologicalPhilosophy.» in: Journal of the History of Ideas, 3 (1994), 505 (traducción propia).

19 Ibid., p. 506.

20 Ibid.

21 Ibíd., p. 507.

22 Ibíd., p. 509. 
Como puede verse, la posibilidad de entender la filosofía de Ortega como una filosofía eminentemente ecológica ya ha sido defendida en numerosas ocasiones y contextos. No obstante, estas reivindicaciones — con la excepción relativa de Rogers- no habían pasado de breves apuntes, y a la bibliografía orteguiana le faltaba un trabajo que abordara sistemática y pormenorizadamente la conexión entre Ortega y la ecología. Esta carencia ha sido recientemente subsanada con la decisiva tesis doctoral de Joshua Beneite-Martí23 , en la cual encontramos una aproximación rigurosa y exhaustiva a la filosofía orteguiana y su relación con la ecología.

En un texto de 2015, Beneite-Martí ya había afirmado que «Ortega es el gran olvidado de la fundamentación filosófica de la ecología» ${ }^{24}$, criticando, con razón, el hecho que las bases filosóficas de la ecología siempre se hayan buscado en autores como Marx o Heidegger, cuando la filosofía de Ortega por su raigambre biológica, como veremos- se prestaba mucho mejor a esta labor de fundamentación ${ }^{25}$. La tesis doctoral a la que hacíamos referencia es si cabe más clara en este sentido, llegando a sostener que «Ortega presentó un enfoque pionero en materia de filosofía ecológica» ${ }^{26}$ y que «la aportación de Ortega a la filosofía ecológica debe ocupar un lugar preponderante» ${ }^{27}$. Beneite-Martí también afirmará, con amplias pruebas, que "Ortega es un lector de ecología ${ }^{28}$, como demuestran sus amplias lecturas no sólo de Uexküll, sino también de otros biólogos como el propio Haeckel, el autor que precisamente acuña la palabra "ecología». A esta conclusión Beneite-Martí también añadirá las ideas de que «Ortega integra y aplica un conocimiento ecológico en su obra» ${ }^{29}$ y que "Ortega contribuyó al desarrollo de la ecología» ${ }^{30}$, conclusiones que refuerzan la conexión de Ortega y la ecología que venimos defendiendo.

No vamos a detenernos más en esta cuestión, pues queda claro que la idea de un Ortega ecologista no es imposible, ni tan siquiera rara, dada la cantidad de autores que la han defendido ${ }^{31}$. Especialmente tras la mencionada tesis doctoral de Beneite-Martí, se hace inexcusable rescatar a Ortega como padre filosófico de la ecología. Este punto, difícilmente discutible desde un punto de

23 Beneite-Martí, J., José Ortega y Gasset y Ramon Margalef i López. Dos fuentes para la constitución de una perspectiva ecológica (tesis doctoral), Universitat de València, Valencia 2017.

24 Beneite-Martí, J., «Ortega, ¿una alternativa para la filosofía ecológica?» en: Tales. Revista de Filosofía, 5 (2015) 97.

25 Cf. Beneite-Martí, J., José Ortega... op. cit., p. 509.

26 Ibíd., p. 508.

27 Ibid., p. 509.

28 Ibíd., p. 510.

29 Ibíd.

$30 \quad$ Ibíd.

31 Como declara Rogers, «el desarrollo por parte de Ortega de una nueva filosofía de la razón vital, de una filosofía ecológica, merece mayor reconocimiento y apreciación» RogeRs, K. W., «Ortega and EcologicalPhilosophy.» in: Journal of the History of Ideas 3 (1994) 522. 
vista estrictamente cronológico, se vuelve problemático cuando se atiende a la diversidad de ecologías existentes hoy en día. Como apuntábamos al principio, la virtud de Ortega, y de la fecha tan temprana en la que pone en marcha su filosofía ecológica, reside precisamente en que nos permite volver a la casilla de salida, a un punto cero de la fundamentación ecológica que, como intentaremos mostrar, nos permite retomar algunos problemas bio-ecológicos radicales. Para mostrar este punto se hace inexcusable atender a las raíces biológicas de la filosofía orteguiana, raíces que lo son también de su propuesta ecológica.

\section{LA BASE BIOLÓGICA DE LA FILOSOFÍA ORTEGUIANA}

La influencia de la biología en el pensamiento de Ortega ha sido muchas veces cuestionada, tanto en su peso específico, como en su significación para la filosofía orteguiana. La tesis más asentada es la esbozada por autores como Orringer $^{32}$ y Cerezo $^{33}$, según la cual habría unos primeros años en los que se infiltra en Ortega un cierto vocabulario biologicista, a través principalmente de Nietzsche, que finalmente se iría depurando y acabaría desapareciendo en una etapa posterior, más madura, de su pensamiento. Esta comprensión, si bien acierta en la influencia de Nietzsche y en los cambios que a principios de los años treinta experimenta la idea de vida orteguiana, yerra, a nuestro entender, al minimizar inadecuadamente el papel de la biología en la conformación y desarrollo del proyecto filosófico orteguiano. Como mostraremos a lo largo de las siguientes líneas, el influjo que las nuevas ciencias biológicas de la segunda mitad del XIX y principios del XX tuvieron en Ortega fue enorme; y su reapropiación a la altura de los años treinta no supuso una negación de la base biológica de su pensamiento, sino un enriquecimiento y ampliación de la misma.

Tal es la importancia de la biología en Ortega que podría entenderse, sin violentar realmente su sentido, que el epíteto de razón vital con el que Ortega calificaba su propia filosofía no es más que la transcripción de la palabra compuesta «bio-logía», el logos del biós. Como explica M. Garrido, «Ortega comentó en repetidas ocasiones que la teoría general de la vida humana podría denominarse biología, siempre que se estuviese de acuerdo en reservar para la biología de los biólogos el nombre de "zoología" »" ${ }^{34}$ una confusión reduccionista entre biós y zoé que, por ejemplo, también ha denunciado J. E. Pérez Pinto ${ }^{35}$. El

32 Cf. Orringer, N., Ortega y sus fuentes germánicas, Gredos, Madrid 1979.

33 Cf. Cerezo Galán, P., La voluntad de aventura. Aproximamiento crítico al pensamiento de Ortega y Gasset, Ariel, Barcelona 1984.

34 GaRrido JimÉnEZ, M., «El yo y la circunstancia» en: Teorema, vol. XIII, nº 3-4 (1983) 335.

35 Pérez Pinto habla de «su distinción entre una auténtica Ciencia de la vida y la Biología, a la que, según Ortega, debería llamarse más bien Zoología» Pérez Pinto, J. E., «Connotaciones biológicas en la obra de Ortega» en: Conversaciones sobre Ortega (Actas de las $1^{\circ}$ jornadas culturales de Aller.), Aller, I.N.B. Príncipe de Asturias, Serie: Temas Alleranos, 1 (1983) 272. 
propio Ortega hablaba de la necesidad de «una teoría general de la vida - cuyo nombre más natural debía ser "Biología” si Lamarck no lo hubiera inventado y acotado para lo que, en rigor, debiera llamarse "Zoología”» (VI 782), un error que según Ortega se debió a que Lamarck "no sabía griego e ignoraba que bios no es, como zoe, vida orgánica, sino conducta del ser viviente» (VI 782). Aranguren incluso irá más lejos, afirmando respecto de Ortega que «cabría decir, un tanto unilateralmente, pero no sin verdad, que su obra consistió en una ontologización de esta biología» ${ }^{36}$.

Manuel Benavides, el autor que más y mejor ha tratado esta relación de Ortega con la biología de su tiempo, comienza su decisiva obra De la ameba al monstruo propicio. Raíces naturalistas del pensamiento de Ortega y Gasset con esta luminosa reflexión:

«Buscar las raíces del pensamiento orteguiano en el estado propio de las ciencias de su tiempo (biología, psicología animal, física, matemática, etnología, historia) significa entroncarle con los más altos momentos de la filosofía occidental; aquellos en que la reflexión, adueñándose de los resultados alcanzados por una revolución científica, elaboró conceptualmente una nueva visión del mundo, que afectaba por igual a la metafísica, a la teoría del conocer, a la ética, a la estética y a una teoría general del hombre» ${ }^{37}$

Benavides piensa que establecer esta conexión del pensamiento orteguiano con las ciencias de su tiempo no sólo no lo rebaja, sino que lo pone al nivel de los mejores y más altos momentos de la filosofía. Este autor entiende, con toda razón, que las ideas «necesitan, como Anteo, tocar tierra, y en especial, la tierra firme de la ciencia» ${ }^{38}$. Si volvemos al caso particular de la biología y la ecología, es evidente, como dice Pérez Pinto, que «La pasada centuria y la presente coinciden con el más espectacular desarrollo de las ciencias biológicas ${ }^{39}$. La filosofía necesariamente tuvo que hacerse eco de estos avances biológicos. Como explica A. Diéguez, esta defensa de la importancia filosófica de la ciencia y en concreto de la biología puede observarse en otros autores de finales del siglo XIX y principios del siglo XX, como Nietzsche, Lorenz, Poincaré, Mach, James, Simmel o Haeckel ${ }^{40}$. En el caso que nos ocupa, como explica Benavides, «el pensamiento de Ortega, especialmente a partir de 1913,

36 Aranguren, J. L., «Ecología y comunicación en el pensamiento de Ortega.» en: Sistema 1 (1973) 53.

37 Benavides Lucas, M., De la ameba al monstruo propicio. Raíces naturalistas del pensamiento de Ortega y Gasset, Ediciones de la Universidad Autónoma de Madrid, Madrid 1988, p. 13.

38 Ibíd., Benavides afirma que «[los conceptos] en el caso de un pensador de raza, tienen siempre raíces terrestres» (p. 9), y menciona algunos de los casos más paradigmáticos: la metafísica platónica reflexiona sobre geometría; la filosofía Aristotélica tiene como base a la biología; Descartes teoriza en base a la nuova scienza de Galileo; Kant forja una metafísica al rebufo de la física de Newton.

39 Pérez Pinto, J. E., op. cit. p. 263

40 Diéguez Lucena, A., La vida bajo escrutinio. Una introducción a la filosofía de la biología, Biblioteca Buridán, Barcelona 2012, p. 301. 
tiene su fuente de inspiración en las ciencias naturales, y que las cesuras que en el mismo pueden determinarse tienen su origen en el cambio de estatuto teórico de aquéllas» ${ }^{41}$.

No es casualidad que muchas de las grandes figuras en biología de principios del siglo pasado sean precisamente algunos de los autores que Ortega más estudió y cuyas ideas situó en el núcleo de su pensamiento. Además de los fundamentales Uexküll y Köhler, Benavides menciona a toda una serie de autores que, en mayor o menor medida, dejaron su impronta en Ortega. Biólogos o teóricos de la biología como el darwinista Haeckel; críticos de Darwin como Driesch, Jennings, Radl ${ }^{42}$, Hugo de Vries o Bateson; médicos y científicos españoles como su amigo Marañón ${ }^{43}$ o Achúcarro; miembros de la Gestalt como el mencionado Köhler o Koffka ${ }^{44}$, antropólogos como Scheler, Plessner o Gehlen; y autores de diversa índole como Klages, Lessing, Bachofen, Dacqué o Goldsmith ${ }^{45}$, los cuales marcaron sus reflexiones sobre el origen del hombre.

A la lista de Benavides podrían incluirse algunos otros nombres importantes, como Turró, el médico español que hizo germinar en Ortega la idea del verdávoro ${ }^{46}$; Lloyd Morgan, quien le proporcionaría importantes ideas sobre la naturaleza instintiva animal; o N. Hartmann, el por entonces joven profesor adjunto con el que Ortega trabó amistad en Marburgo y que ya en 1912 había escrito Cuestiones fundamentales filosóficas de la biología (Cf. Hartmann, 1912), un libro que se encuentra en la biblioteca personal de Ortega anotado profusamente por él mismo y que está dedicado afectuosamente por Hartmann.

La idea fundamental a la que Ortega llega a través de la biología de su tiempo - principalmente a través de la apropiación filosófica, creativa, de algunas ideas de Uexküll—, es la de que la metafísica tradicional, con su tradicional distinción entre sujeto y objeto, había quedado obsoleta y debía ser superada. La idea «yo soy yo y mi circunstancia», algo tosca en su enunciación, encerraba, no obstante, una significación y fecundidad extraordinarias. Pues lo que esta tesis suponía, pese a su aparente sencillez, era un trastocamiento radical de las categorías metafísicas clásicas. Yo y circunstancia debían ser pensados en términos de relación dinámica, de co-implicación e inseparabilidad: el yo dependía en su ser y estaba conformado por la circunstancia; pero la circunstancia, a su vez - -y esto era y es, quizás, lo más difícil de pensar-, también dependía

41 Benavides Lucas, M., op. cit., p. 18.

42 «Hay, pues, que suponer que, pese a sus olvidos, los estudios en Leipzig y el contacto con tan eximio exponente de la biología le proporcionaran un notable conocimiento de esta ciencia». Benavides LucAs, M., op. cit., p. 26.

43 Benavides Lucas, M., op. cit., pp. 157-158.

44 Ibíd., p. 300.

45 Ibid., p. 12.

46 Que Ortega conoció la obra de Turró Orígenes del conocimiento: el hambre es altamente probable, dado que Unamuno hace el prólogo a dicha obra y sobre todo por las conferencias en la residencia de estudiantes que Turró impartió en 1917, que fueron posteriormente publicadas en 1918. 
ontológicamente del yo. Esta idea le llevará, en un importante curso de 1930 titulado ¿Qué es la vida?, a decir que:

"La circunstancia es tal cual es porque o en vista de que yo he decidido ser profesor o Doctor en Filosofía o intelectual dueño de mí mismo. Este añadido es de suma importancia. No sólo mi circunstancia y yo somos ahora lo que somos porque he decidido ser filósofo y en vista de ello he venido aquí, sino que una vez dentro de este aula lo que para mí existe de ella depende de aquella decisión» (VIII 432).

El yo, que en la metafísica orteguiana de madurez equivale al proyecto de vida, no sólo modifica la circunstancia, sino que la conforma, le da realidad. Como dice en otro pasaje de este mismo curso, la circunstancia no es nada por sí misma, sino que «consiste en la respuesta cósmica a mi presión proyectiva sobre ella» (VIII 437-438). El yo y su circunstancia, el organismo y su entorno, quedan así no sólo indisolublemente entrelazados, sino que a partir de ese momento aparecían en una relación de inter-dependencia tan estrecha, que la propia separación entre ambos quedaba difuminada y puesta en duda. Esta consecuencia, que Ortega fue reconociendo poco a poco al profundizar en su filosofía, le llevó, a finales de los años veinte y principios de los treinta, a enfatizar tanto la circunstancialidad de parte del yo - «me encuentro al encontrarme en la vida con mi cuerpo ni más ni menos que me encuentro con la sierra del Guadarrama y con esta mesa» (VIII 392)_, como a remarcar la impregnación del yo en la circunstancia — «[el yo] hace que lo otro -el mundose vaya convirtiendo poco a poco en él mismo. El hombre humaniza al mundo, le inyecta, lo impregna de su propia sustancia ideal»(V 537-538)—. Estas dos vertientes, paradójicas pero no por ello contradictorias, muestran cómo Ortega verdaderamente estaba adentrándose en terra incognita y en muchos casos encontraba grandes dificultades para conceptualizar satisfactoriamente lo que todavía no veía con claridad y sólo podía palpar tentativamente con sus manos.

\section{ORGANISMO Y ENTORNO: UNA PROPUESTA BIO-ECOLÓGICA}

Algunos de los últimos avances en biología apuntan precisamente en esta dirección que Ortega logró atisbar, y pensamos que una ecología radical, una ecología que sea capaz de abordar filosóficamente estos problemas, debe preguntarse hasta qué punto tiene sentido contraponer de manera tajante la actividad ecológica humana y la del resto de seres vivos; y, particularmente, hasta qué punto es lícito utilizar esta contraposición como principal argumento en la querella medioambiental que el ser humano se ha lanzado a sí mismo en los últimos años. Para fundamentar este argumento, expondremos muy sucintamente algunas de las ideas clave a las que los más recientes estudios biológicos sobre el tema han llegado, mostrando hasta qué punto la propuesta orteguiana estaba en el camino más acertado y fecundo en lo que respecta a la ecología. 
La reciente publicación en 2015 de Organismo y entorno (Organism and Environment: Ecological development, Niche Construction, and Adaptation ${ }^{47}$ ), por parte de Sonia Sultan ha condensado el concienzudo trabajo biológico de las últimas décadas sobre el problema que venimos discutiendo. Y la conclusión a la que llega no podría ser más orteguiana: organismo y entorno deben ser repensados y estudiados como parte de un continuo, en lugar de considerarse, como ha sido habitual hasta ahora, como «entidades separadas» ${ }^{48}$. Esto es así porque «el entorno se extiende en el organismo y el organismo en el entorno, de forma que se difumina la barrera entre ambos y nos encontramos, más bien, con íntimas y causalmente multidireccionales interacciones biológicas» ${ }^{49}$. Sultan cita al filósofo de la biología Russell Gray, quien habló de la «coconstrucción ${ }^{50}$ de organismo y entorno; y también toma como referencia al paleontólogo George Simpson, quien en una fecha temprana (1953) enfatizó la necesidad de centrarse «no tanto en el entorno o en los organismos, como en la compleja interrelación entre ambos, interrelación que realmente no admite separación ${ }^{51}$. Como hemos visto, Sultan todavía podría haber encontrado un antecedente más antiguo de esta postura en Ortega. En cualquier caso, la propuesta de esta autora resulta extremadamente interesante, principalmente por la cantidad de trabajo biológico que aprovecha para fundamentar sus ideas. La idea principal de Organismo y entorno queda expuesta muy al principio al afirmar que:

«Un torrente de nuevas ideas e investigaciones ha revelado, como nunca antes, la íntima y causal relación que vincula a los organismos y sus entornos. El desarrollo está modulado - de maneras increíblemente complejas- por modificaciones epigenéticas inducidas ${ }^{52}$, por la nutrición parental y los niveles de estrés, por condiciones químicas y físicas a nivel celular, y por una enorme cantidad de otros factores y retroalimentaciones ambientales. De la misma manera en que el entorno participa en el modelado del organismo, la presencia, actividades, productos y subproductos del organismo modifican ese entorno ${ }^{53}$.

47 Sultan, S. E., Organism and Environment: Ecological development, Niche Construction, and Adaptation, Oxford Scholarship Online, Oxford 2015.

${ }_{48}$ Ibid., p. 31 (traducción propia).

49 Ibid.

50 GraY, R., «Death of the gene: Developmental systems strike back» in: GraY, R.D. and Griffiths, P. (eds.), Trees of Life: Essays in the Philosophy of Biology, Kluwer Publishing, Dordrecht 1992, pp. 165-209.

51 Simpson, G. G., Major Features of Evolution, Simon and Schuster, New York 1953, p. 199 (traducción propia).

52 Introducir aquí y dar cuenta del interesantísimo e innovador campo de la epigenética sería imposible, pero baste apuntar que podría considerarse una prueba más de la necesidad de romper las barreras entre organismos y entornos, estudiando más bien la intersección entre ambos. Como introducción al tema puede consultarse Pérez, D., "Yo soy yo y mi circunstancia (epigenética).» en: Escritura Pública, 5-6 (2015), 69-74, un breve texto divulgativo que, no casualmente, homenajea a Ortega en su título.

53 Sultan, S. E., op. cit., p. xiii (traducción propia). 
Sultan explica cómo dos disciplinas biológicas han ido surgiendo en paralelo debido al reconocimiento de esta mutua e insoslayable imbricación entre organismo y entorno. Por una parte, «el reconocimiento del rol del entorno en el modelado de la expresión génica y, por tanto, en los fenotipos individuales, ha dado lugar a la emergencia de una «biología ecológica del desarrollo» (ecological developmental biology)» ${ }^{54}$, siendo las referencias más importantes sobre esta disciplina Gilbert (2001) 55 ; Sultan $(2007)^{56}$; y Gilbert y Epel (2009) ${ }^{57}$. Por otra parte, la disciplina centrada en la otra vertiente, la que se interesa por los efectos de los organismos en sus entornos, se ha venido a llamar «teoría de la construcción del nicho» (niche construction) ${ }^{58}$, y sus máximos representantes serían Lewontin $(1983)^{59},(2000)^{60}$; Odling-Smee et al. (2003) ${ }^{61}$ y Scott-Phillips et al. $(2013)^{62}$. La principal tesis que Sultan defenderá y sobre la que hará gravitar su obra es que estas dos líneas de investigación deben converger; pues, para entender esta «relación dinámica y recíproca ${ }^{63}$ —palabras idénticas a las de Ortega-, se deben tener en cuenta de manera conjunta la influencia de los organismos sobre los entornos y de los entornos sobre los organismos.

La autora no escatima en ejemplos, pero, por mor de la brevedad, nos detendremos sólo en uno de ellos, que además sería con toda seguridad muy del gusto de Ortega, quien ya sacó enorme provecho de las reflexiones sobre las amebas de Uexküll y otros biólogos. Sultan expone el caso de una babosa, la babosa verde de mar, que se caracteriza por succionar los filamentos de un alga reteniendo unos cloroplastos que incorpora a las células de su tracto digestivo y que le permiten llevar a cabo la fotosíntesis (y le dan su color verde brillante a la babosa). De ahí en adelante, este molusco vive prácticamente como un alga nutriéndose mediante la fotosíntesis que los cloropastos ingeridos llevan a cabo ${ }^{64}$. A raíz de este curioso caso, Sultan se pregunta: «¿es el alga parte del

$54 \quad$ Ibid.

55 Gilbert, S. F., «Ecological developmental biology: Developmental biology meets the real world» in: Developmental Biology, 233 (2001) 1-12.

56 Sultan, S. E., «Development in context: The timely emergence of eco-devo» in: Trends in Ecology and Evolution, 22 (2007) 575-582.

57 Gilbert, S. F., and Epel. D., Ecological Developmental Biology: Integrating Epigenetics, Medicine, and Evolution, Sinauer Associates, Sunderland 2009.

58 Sultan, S. E., Organism... op. cit., p. xiii (traducción propia).

59 Lewontin, R. C., «Gene, organism and environment» in: Bendall, D.S. (ed.), Evolution: From Molecules to Men, Cambridge University Press, Cambridge 1983, pp. 273-285.

60 Lewontin, R. C., The Triple Helix: Gene, Organism and Environment, Harvard University Press, Cambridge 2000.

${ }_{61}$ Odling-Smee, F. J, Laland, K., Feldman, M., Niche-construction: The Neglected Process in Evolution, Princeton University Press, New Jersey 2003.

62 Scott-Phillips, T. C., Laland, K.N., Shuker, D.M., Dickins, T.E., and West, S.A., «The niche construction perspective: A critical appraisal» in: Evolution, 68 (2013), 12331-11243.

63 Sultan, S. E., Organism... op. cit., p. xiii (traducción propia).

64 Rumpho, M. E., Summer, E.J. and Manhart, J.R., «Solar-powered sea slugs: Mollusc/algal chloroplast symbiosis» in: Plant Physiology, 123 (2000), 29-38; Rumpho, M. E., Worful, J.M., LEE, J., et al., "Horizontal gene transfer of the algal nuclear gene psbO to the photosynthetic 
entorno del molusco, o es parte del propio animal?» Y la respuesta que da es: «ambos, realmente» ${ }^{65}$. La explicación consiste en que «el animal incorpora su entorno (biótico) en su desarrollo de la manera más profunda posible. (...) El entorno construye a la babosa verde de mar, y la babosa verde de mar construye su entorno ${ }^{66}$.

Este ejemplo muestra a las claras la necesidad de repensar la relación entre los organismos y sus entornos, o en términos más orteguianos y metafísicos, entre el yo y la circunstancia. Pues si bien el caso de la babosa verde de mar es extremo, en el fondo todo ser vivo entabla una relación activa, dinámica, y por ende transformadora (en un doble, recíproco, sentido), con su entorno. Como expone Sultan, desde hace años existe una disciplina conocida como «teoría de la construcción del nicho" que precisamente estudia "cómo los animales y otros organismos pueden modelar las condiciones de su existencia, ya sea por medios de sus procesos metabólicos, sus actividades, o los comportamientos que alteran físicamente las variables ambientales ${ }^{67}$. Los trabajos más representativos de esta línea de investigación sobre la «teoría de la construcción del nicho» son los de Odling-Smee et al. (2003) y Laland and Sterelny (2006) ${ }^{68}$; pero en realidad hay muchas investigaciones biológicas convergentes que han dado cuenta de esta realidad constructiva de los seres vivos. Un caso conocido desde hace décadas es el de innumerables especies de hormigas y termitas que no sólo son capaces de erigir enormes construcciones, sino que transforman de manera sustancial su entorno, alterando las propiedades del suelo, su temperatura, humedad, y otras muchas características ${ }^{69}$. Pero los ejemplos serían literalmente interminables. Pues, en realidad, como explica Sultan:

«Los efectos de los organismos en sus entornos son ubicuos, tanto a nivel individual como a nivel colectivo, tanto a corto plazo como a eones de distancia temporal. Cada planta, animal, bacteria, célula de levadura, u organismo de cualquier índole incorpora recursos y expulsa residuos, ocupa espacio, absorbe o irradia energía, etc. Sean estos impactos externos beneficiosos o perjudiciales para el propio organismo, en ambos casos estos impactos modelan inevitablemente las condiciones funcionales y evolutivas de ese hábitat» ${ }^{70}$.

sea slug Elysia chlorotica» in: Proceedings of the National Acadamy of Sciences USA, 105 (2008) 17867-17871; Rumpho, M. E., Pelletreau, K.N., Moustafa, A., and Bhattacharya, D., «The making of a photosynthetic animal» in: Journal of Experimental Biology, 214 (2011) 303311; Venn, A. A., Loram, J. E., and Douglas, A. E., "Photosynthetic symbioses in animals» in: Journal of Experimental Biology, 59 (2008) 1069-1080.

65 Sultan, S. E., Organism... op. cit., p. 32 (traducción propia).

66 Ibíd.

67 Ibíd., p. 37 (traducción propia).

68 LALAND, K. N., and STERELNY, K., «Seven reasons not to neglect niche construction» in: Evolution, 60 (2006) 1751-1762.

69 Hölldobler, B; Wilson, E. O., Viaje a las hormigas, Crítica, Barcelona 1996. DE BRuyn, L. A., and Conacher, A. J., "The role of termites and ants in soil modification: A review» in: Australian Journal of Soil Research, 28 (1990) 55-93.

70 Sultan, S. E., Organism... op. cit., p. 93 (traducción propia). 
De este modo, llegamos a la conclusión de que, no sólo la vida humana es un "problema de ingeniero», como Ortega dejó dicho en su Meditación de la técnica (V 575), sino que toda vida consiste en un problema ingenieril de este tipo. La palabra «ingeniero», que, como comenta Sultan, a muchos les resulta «antropomórfica» ${ }^{71}$, es en realidad el término adecuado para referirse a la forma en que todo organismo se relaciona con su entorno ${ }^{72}$. La acción humana tiene sus propias características específicas, por supuesto; pero la distinción no puede trazarse en términos simplistas entre una especie activa que transforma y daña su entorno - el ser humano-, y el resto de seres vivos, los cuales habitarían pasiva y armónicamente su entorno. Esta dicotomía es falsa y supone un obstáculo a una adecuada comprensión de estos cruciales problemas que nos trae la ecología.

\section{Conclusiones}

Así pues, desde esta perspectiva, la profusa tipología de éticas ambientales, la distinción entre éticas ambientales antropocéntricas y fisiocéntricas; biocéntricas, o ecocéntricas ${ }^{73}$, quedaría, en cierto modo, cuestionada. Hablar de antropo-centrismo o de fisio-centrismo; de bio-centrismo o eco-centrismo, es ya errar el tiro: sin organismo no hay entorno, y sin entorno no hay organismo, razón por la cual situar a uno u otro en el centro implica comenzar la reflexión desde un equívoco. Organismo y entorno ${ }^{74}$, están indisolublemente unidos, y ni siquiera puede pensarse uno al margen del otro: el logos sobre el oikos necesariamente ha de ser también, al mismo tiempo, el logos sobre el bios. Por eso la ecología debe convertirse, como decíamos al principio y argumenta también Sultan, en bio-ecología.

${ }_{71} \quad$ Ibíd., p. 96 (traducción propia).

72 Ya hay una extensa literatura que se refiere a ciertas especies animales especialmente activas como «ingenieros de ecosistemas»: Jones, C. G., Lawton, J. H., and SHachaK, M., "Organisms as ecosystem engineers» in: Oikos, 69 (1994) 373-386; Jones, C. G., Lawton, J. H., and Sнаснак. M., "Positive and negative effects of organisms as physical ecosystem engineers» in: Ecology, 778 (1997) 1946-1957; Boogert N. J., Paterson, D. M. and Laland, K. N., "The implications of niche construction and ecosystem engineering for conservation biology» in: BioScience, 56 (2006) 570-578. Wright, J. P., and C. G. JonES, C. G., «The concept of organisms as ecosystem engineers ten years on: Progress, limitations, and challenges» in: Bioscience, 56 (2006) 203-209.

73 Beneite-Martí, J., José Ortega... op. cit., pp. 115-116.

74 De hecho, seguramente haríamos bien en abandonar la palabra «entorno», que inadvertidamente hace recaer el peso en el organismo "en torno"” al cual surge ese entorno, cuando lo que queremos es destacar el papel activo, conformador, de dicho entorno. Nicho ecológico, al ser un término más técnico, resulta más atractivo. Pero, en último término, adolece del mismo problema, pues la palabra nicho carga también con una connotación pasiva y estática. Como ya dijo Ortega, nuevas ideas requieren nuevas palabras, o quizás rescatar y reinventar viejas palabras como oikos. En todo caso, esta tarea de crear nuevos términos desborda los propósitos de este trabajo, por lo que dejamos esta tarea como pendiente. 
Una ecología a la altura de nuestro tiempo debe ser, como ha puesto de manifiesto recientemente Agustín Domingo Moratalla, una ecología «integral $»^{75}$. Como explica este autor, la ecología integral tiene un «carácter "holístico" $»^{76}$ y nos "permite discriminar en el río revuelto de las ecologías» ${ }^{77}$. Domingo Moratalla, desde coordenadas bastante distintas a las de este trabajo, aboga, no obstante, por una salida similar a la que aquí defendemos, en la cual se alcance un equilibrio entre un "humanismo ideológico» y un "ecologismo biocéntrico» ${ }^{78}$, un equilibrio que nos permita pensar ambos polos de la realidad de manera conjunta y no simplificadora.

En este sentido, nos parece muy acertada la reivindicación de la Laudato si del Papa Francisco ${ }^{79}$ que Agustín Domingo Moratalla lleva a cabo. Pues el texto de Francisco tiene la virtud de evitar los extremos que demonizan al ser humano y su técnica ${ }^{80}$, que asumen como algo dado la brutalidad de su naturaleza y dejan un poso de desesperanza y nihilismo tan desmoralizante como falso. Como venimos repitiendo a lo largo de este texto, hay que partir del reconocimiento de que el hombre, como el resto de seres vivos, se encuentra siempre y de manera insuperable en una relación dinámica y transformadora de su entorno. No cabe plantearse hipótesis paralíticas o de desasimiento: si el hombre - o cualquier otro ser vivo - ha de vivir, tiene necesariamente que intervenir en su entorno. Mas, esta es la cuestión, hay muchas maneras de intervenir, y lo que tenemos que buscar son modos en que esta imprescindible actividad constructora, creadora de nichos y hábitats, sea tan humana como ecológica; que sea, en definitiva, «integral» y no deje fuera ningún aspecto de la realidad. Como afirma Domingo Moratalla, un buen sinónimo de ecología integral es responsabilidad ${ }^{81}$. Y debemos responsabilizarnos, no (sólo) porque sea lo correcto desde un punto de vista moral, sino porque, al ser el entorno una parte indisoluble de nosotros mismos, cuidarlo significa cuidarnos, y en hacerlo acertadamente nos va, no sólo la vida, sino también la felicidad.

\section{BiBLIOGRAFía}

Álvarez, M. (1998). «El concepto de cosa en Ortega.» en: PARedes, M ${ }^{\mathrm{a}}$ C., El hombre y su medio. Perspectivas ecológicas desde Ortega y Gasset. Salamanca: Publicaciones Universidad Salamanca.

75 Domingo Moratalla, A., Condición humana y ecología integral, PCC, Madrid 2017

76 Ibid., p. 64.

77 Ibid., p. 59.

78 Ibid., p. 63.

79 Bergoglio, J. M., Laudato si. Sobre el cuidado de la casa común, Palabra, Madrid 2015.

80 Domingo Moratalla, A., op. cit., pp. 50-52.

81 Ibid., p. 63. 
Aranguren, J. L. (1973). «Ecología y comunicación en el pensamiento de Ortega.» en: Sistema. Revista de Ciencias Sociales, n 1, pp. 51-58.

Bellver, V. (1994). Ecología: de las razones a los derechos. Granada: Comares.

Beneite-Martí, J. (2015). «Ortega, ¿una alternativa para la filosofía ecológica?» en: Tales. Revista de Filosofía, 5, pp. 97-115.

—, José Ortega y Gasset y Ramon Margalef i López (2017). Dos fuentes para la constitución de una perspectiva ecológica (tesis doctoral). Valencia: Universitat de València.

Bergoglio, J. M. (2015). Laudato si. Sobre el cuidado de la casa común. Madrid: Palabra.

Begon, M., Harper, J. and Townsend, C. (1990). Ecology: Individuals, Populations, and Communities. Oxford: Blackwell Science.

Boogert N. J., Paterson, D. M. and Laland, K. N. (2006). «The implications of niche construction and ecosystem engineering for conservation biology» in: BioScience, 56, pp. 570-578.

Benavides Lucas, M. (1988). De la ameba al monstruo propicio. Raíces naturalistas del pensamiento de Ortega y Gasset. Madrid: Ediciones de la Universidad Autónoma de Madrid.

Cerezo Galán, P. (1984). La voluntad de aventura. Aproximamiento crítico al pensamiento de Ortega y Gasset. Barcelona: Ariel.

de Bruyn, L. A., and Conacher, A. J. (1990). «The role of termites and ants in soil modification: A review» in: Australian Journal of Soil Research, 28, pp. 55-93.

Diéguez Lucena, A. (2012). La vida bajo escrutinio. Una introducción a la filosofía de la biología. Barcelona: Biblioteca Buridán.

Domingo Moratalla, A. (2017). Condición humana y ecología integral. Madrid: PCC.

Durán, M. (1996). «Ortega y von Uexküll: de la biología a la razón vital» en: Revista canadiense de estudios hispánicos, vol. 21, nº 1, pp. 101-116.

Espinosa Rubio, L. (1998). «La técnica como radical ecología humana» en: PAREdEs, $M^{\mathrm{a}}$ C., El hombre y su medio. Perspectivas ecológicas desde Ortega y Gasset. Salamanca: Publicaciones Universidad Salamanca, pp. 119-142.

Garrido Jiménez, M. (1983). «El yo y la circunstancia» en: Teorema, vol. XIII, nº 3-4, pp. 309-343.

Gehlen, A. (1980). El hombre: su naturaleza y su lugar en el mundo. Salamanca: Sígueme.

Gilbert, S. F. (2001). «Ecological developmental biology: Developmental biology meets the real world» in: Developmental Biology, 233, pp. 1-12.

Gilbert, S. F., and Epel. D. (2009). Ecological Developmental Biology: Integrating Epigenetics, Medicine, and Evolution. Sunderland: Sinauer Associates.

Gray, R. (1992). «Death of the gene: Developmental systems strike back» in: Gray, R.D. and Griffiths, P. (eds.), Trees of Life: Essays in the Philosophy of Biology. Dordrecht: Kluwer Publishing, pp. 165-209.

Hartmann, N. (1912). Philosophische Grundfragen der Biologie. Göttingen: Dambenhoed \& Ruprecht.

Hölldobler, B., Wilson, E. O. (1996). Viaje a las hormigas. Barcelona: Crítica.

Jones, C. G., Lawton, J. H., and Shachak, M. (1994). «Organisms as ecosystem engineers» in: Oikos, 69, pp. 373-386.

Jones, C. G., Lawton, J. H., and Shachak. M. (1997). «Positive and negative effects of organisms as physical ecosystem engineers» in: Ecology, 778, pp. 1946-1957.

Jordano Barea, D. (1983). «Ortega y la ecología de Jacobo von Uexküll.» en: Boletín de la Real Academia de Córdoba, no 105, pp. 108-111.

Laland, K. N., and Sterelny, K. (2006). «Seven reasons not to neglect niche construction» in: Evolution, 60, pp. 1751-1762. 
Lewontin, R. C. (2000). The Triple Helix: Gene, Organism and Environment. Cambridge: Harvard University Press.

«Gene, organism and environment» in: Bendall, D. S. (ed.) (1983). Evolution: From Molecules to Men. Cambridge: Cambridge University Press, pp. 273-285.

Odling-Smee, F. J, Laland, K., Feldman, M. (2003). Niche-construction: The Neglected Process in Evolution. New Jersey: Princeton University Press.

Orringer, N. (1979). Ortega y sus fuentes germánicas. Madrid: Gredos.

Ortega y Gasset, J. (2004-2010). Obras completas. Tomos I-X. Madrid: Taurus.

Paredes, $M^{\text {a }}$ C. (ed.) (1998). El hombre y su medio. Perspectivas ecológicas desde Ortega y Gasset. Salamanca: Publicaciones Universidad Salamanca.

Pérez, D. (2015). «Yo soy yo y mi circunstancia (epigenética).» en: Escritura Pública, 5-6, pp. 69-74.

Pérez Pinto, J. E. (1983). «Connotaciones biológicas en la obra de Ortega» en: Conversaciones sobre Ortega (Actas de las $1^{\circ}$ jornadas culturales de Aller.), I.N.B. Príncipe de Asturias (Serie: Temas Alleranos; 1), Aller, pp. 263-273.

Ricklefs, R. (1990). Ecology. New York: W. H. Freeman.

Rogers, K. W. (1994). «Ortega and Ecological Philosophy.» in: Journal of the History of Ideas, 3, pp. 503-522.

Rumpho, M. E., Pelletreau, K. N., Moustafa, A., and Bhattacharya, D. (2011). «The making of a photosynthetic animal» in: Journal of Experimental Biology, 214, pp. 303-311.

Rumpho, M. E., Summer, E. J. and Manhart, J. R. (2000). «Solar-powered sea slugs: Mollusc/algal chloroplast symbiosis» in: Plant Physiology, 123, pp. 29-38.

Rumpho, M. E., Worful, J. M., Lee, J., et al. (2008). «Horizontal gene transfer of the algal nuclear gene psbO to the photosynthetic sea slug Elysia chlorotica» in: Proceedings of the National Acadamy of Sciences USA, 105, pp. 17867-17871.

Scheler, M. (2000). El puesto del hombre en el cosmos. Barcelona: Alba editorial.

Scott-Phillips, T. C., Laland, K.N., Shuker, D.M., Dickins, T.E., and West, S.A. (2013). «The niche construction perspective: A critical appraisal» in: Evolution, 68, pp. 12331-11243.

Shepard, P. (1972). «Introduction.» in: Meditations on hunting. Belgrade: Wilderness Adventure Press, pp. 15-20.

Simpson, G. G. (1953). Major Features of Evolution. New York: Simon and Schuster.

Sultan, S. E. (2007). «Development in context: The timely emergence of eco-devo» in: Trends in Ecology and Evolution, 22, pp. 575-582.

Organism and Environment: Ecological development, Niche Construction, and Adaptation, Oxford Scholarship Online, Oxford 2015.

Venn, A. A., Loram, J. E., and Douglas, A. E. (2008). «Photosynthetic symbioses in animals» in: Journal of Experimental Biology, 59, pp. 1069-1080.

von Uexküll, J. (1945). Ideas para una concepción biológica del mundo. Buenos Aires: Espasa-Calpe.

Wright, J. P., and C. G. Jones, C.G. (2006). «The concept of organisms as ecosystem engineers ten years on: Progress, limitations, and challenges» in: Bioscience, 56, pp. 203-209. 